\title{
AUTHOR INDEX FOR VOLUME 87
}

ALBADAWI, H.; see SHEBRAWI, K.

BERTRAM, E. A.; New reductions and logarithmic lower bounds for the number of conjugacy classes in finite groups

BHATT, S. J. and DABHI, P. A.; Arens regularity and amenability of Lau product of Banach algebras defined by a Banach algebra morphism

BOOS, L. J.; Totally null sets for $A(X)$

BORNA, K. and JAFARI, R.; On a class of monomial ideals

CAO, J. B.; Dunkl-Williams inequalities for integrable functions in Banach space

CHEN, H.-X.; see ZHANG, S.

CRUZ-COTA, A.-H. and RAMIREZ-ROSAS, T.; The complexity of Riemann surfaces and the Hurwitz existence problem

CZÉDLI, G. and KISS, E. W.; Varieties whose tolerances are homomorphic images of their congruences

DABHI, P. A.; see BHATT, S. J.

DAI, L.-X., PAN, H. and TANG, C.-E.; Note on odd multiperfect numbers

DEKA BARUAH, N. and NATH, K.; Infinite families of arithmetic identities for 4-cores

DOLINKA, I.; Finite regular bands are finitely related

DRAGOMIR, S. S.; Some reverses of the Jensen inequality with applications

DUBE, T.; A note on relative pseudocompactness in the category of frames

FARAMARZI SALLES, A.; Finitely generated soluble groups with a condition on infinite subsets

FATHI, A.; Local-global principle for the finiteness and artinianness of generalised local cohomology modules

FOULADI, S. and ORFI, R.; Maximum size of subsets of pairwise noncommuting elements in finite metacyclic $p$-groups

FU, X. and LI, L.; Generating systems of subgroups in $\mathrm{SU}(2,1)$

GHORAISHI, S. M.; A note on automorphisms of finite $p$-groups

HAFEZIEH, R. and IRANMANESH, M. A.; Bipartite divisor graph for the product of subsets of integers

HE, W.; see WANG, H.

HERNÁNDEZ, E. and O’REGAN, D.; Existence results for a class of abstract impulsive differential equations

HOFMANN, K. H. and RUSSO, F. G.; The probability that $x^{m}$ and $y^{n}$ commute in a compact group

IRANMANESH, M. A.; see HAFEZIEH, R. 
JABŁOŃSKA, E.; On continuous solutions of an equation of the GołąbSchinzel type

JAFARI, R.; see BORNA, K.

JAKLIČ, G. and MODIC, J.; Inverse eigenvalue problem for Euclidean distance matrices of size 3

JAMALI, A. R. and VISEH, M.; On the existence of noninner automorphisms of order two in finite 2-groups

JAVANSHIRI, H. and NASR-ISFAHANI, R.; The strong dual of measure algebras with certain locally convex topologies

KISS, E. W.; see CZÉDLI, G.

KLOEDEN, P. E. and KOZYAKIN, V. S.; Asymptotic behaviour of random Markov chains with tridiagonal generators

KONG, Y.; On pairs of linear equations in four prime variables and powers of two

KONIECZNY, J.; Centralisers in the infinite symmetric inverse semigroup 462

KOZYAKIN, V. S.; see KLOEDEN, P. E.

LI, L.; see FU, X.

LIU, J. and ZHANG, J.; Complete spacelike submanifolds in de Sitter spaces with $R=a H+b$

LUKKARINEN, J. and PAKKANEN, M. S.; On the positivity of RiemannStieltjes integrals

MODIC, J.; see JAKLIČ, G.

MUKWEMBI, S. and MUNYIRA, S.; Degree distance and minimum degree

MUNYIRA, S.; see MUKWEMBI, S.

NAKAMURA, T. and PAŃKOWSKI, Ł.; Self-approximation for the Riemann zeta function

NASR-ISFAHANI, R.; see JAVANSHIRI, $\mathrm{H}$.

353

NATH, K.; see DEKA BARUAH, N.

O'REGAN, D.; see HERNÁNDEZ, E.

ORFI, R.; see FOULADI, S.

OSȨKOWSKI, A.; Sharp estimates for functions of bounded lower oscillation

PAKKANEN, M. S.; see LUKKARINEN, J.

PAN, H.; see DAI, L.-X.

PAŃKOWSKI, Ł.; see NAKAMURA, T.

PIERRI, M. and ROLNIK, V.; On pseudo $\mathcal{S}$-asymptotically periodic functions

POURMAHMOOD-AGHABABA, H.; Approximately biprojective Banach algebras and nilpotent ideals

RAMIREZ-ROSAS, T.; see CRUZ-COTA, A.-H.

ROBERTS, D.; Equations with Dirichlet boundary noise 
$\begin{array}{ll}\text { ROLNIK, V.; see PIERRI, M. } & 238\end{array}$

RUSSO, F. G.; see HOFMANN, K. H. 503

SHABANI-ATTAR, M.; Existence of noninner automorphisms of order $p$ in some finite $p$-groups

SHEBRAWI, K. and ALBADAWI, H.; Trace inequalities for matrices

SHPARLINSKI, I.; Correction to 'Sum-product estimates and multiplicative orders of $\gamma$ and $\gamma+\gamma^{-1}$ in finite fields'

SOLTANI, F.; Heisenberg-Pauli-Weyl uncertainty inequality for the Dunkl transform on $\mathbb{R}^{d}$

SPADARO, S.; $P$-spaces and the Volterra property

STEWART, R. and ZHANG, H.; A note concerning the distances of uniformly distributed points from the centre of a rectangle

STROBIN, F. and SWACZYNA, J.; On a certain generalisation of the iterated function system

SUN, L. and WANG, L.; Natural partial order in semigroups of transformations with invariant set

SUN, Z.-H.; Some properties of a sequence analogous to Euler numbers

SWACZYNA, J.; see STROBIN, F.

TANG, C.-E.; see DAI, L.-X.

VERRET, G.; On the order of arc-stabilisers in arc-transitive graphs, II 441

VISEH, M.; see JAMALI, A. R.

278

WANG, H. and HE, W.; Notes on $K$-topological groups and homeomorphisms of topological groups

WANG, L.; see SUN, L.

YANG, F. and YIN, Y.; A new proof of the realisation of cubic tableaux 207

YIN, Y; see YANG, F.

ZHANG, H.; see STEWART, R.

ZHANG, J.; see LIU, J.

ZHANG, S., CHEN, H.-X. and ZHANG, Y.-Z.; Classification of quiver Hopf algebras and pointed Hopf algebras of type one

ZHANG, Y.-Z.; see ZHANG, S.

ZOBEIDI, A.; Every topologically amenable locally compact quantum group is amenable 


\section{CAMBRIDGE}

\section{JOURNALS}

\section{Journal of K-Theory}

Published for Independent Scholarly Online and Print Publishing (ISOPP)

\section{Editor}

Anthony Bak, University of Bielefeld, Germany

Jonathan M. Rosenberg, Department of Mathematics, University of Maryland, USA

Charles Weibel, Department of Mathematics, Hill Center-Busch Campus,

Journal of K-Theory is concerned with developments and applications of ideas and methodologies called K-theory. They have their origin in the work of Alexander Grothendieck in algebraic geometry. Subsequently they have taken hold in various areas of topology, algebra, and analysis and in recent times have contributed to the establishment of noncommutative geometry.

The journal welcomes submissions in any of the areas above where K-theory plays a role. It will also consider well written research-survey articles intended to provide nonspecialists with access and insight into topics of current research.

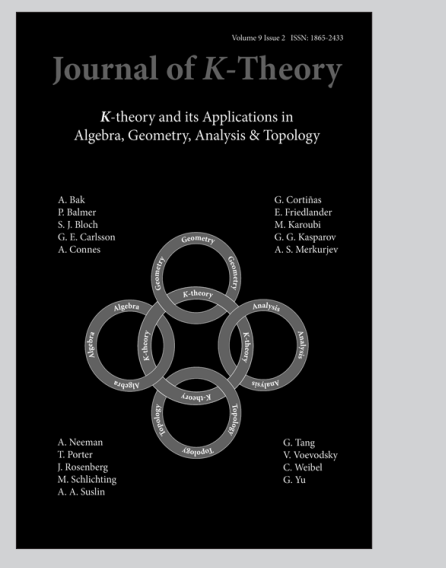

Journal of K-Theory

is available online at:

http://journals.cambridge.org/jkt

\section{To subscribe contact Customer Services}

\section{in Cambridge:}

Phone +44 (0)1223 326070

Fax $+44(0) 1223325150$

Email journals@cambridge.org

\section{in New York:}

Phone +1 (845) 3537500

Fax +1 (845) 3534141

Email

subscriptions_newyork@cambridge.org

\section{Free email alerts}

Keep up-to-date with new material - sign up at

journals.cambridge.org/register 


\section{CAMBRIDGE}

\section{JOURNALS}

\section{Mathematical Proceedings \\ of the \\ Cambridge Philosophical Society}

Published for The Cambridge Philosophical Society

\section{Editor}

G. P. Paternain, University of Cambridge, UK

Mathematical Proceedings is one of the few high-quality journals publishing original research papers that cover the whole range of pure and applied mathematics, theoretical physics and statistics. All branches of pure mathematics are covered, in particular logic and foundations, number theory, algebra, geometry, algebraic and geometric topology, classical and functional analysis, differential equations, probability and statistics. On the applied side, mechanics, mathematical physics, relativity and cosmology are included.

\section{Price information}

is available at: http://journals.cambridge.org/psp

\section{Free email alerts}

Keep up-to-date with new material - sign up at http://journals.cambridge.org/psp-alerts

To subscribe contact Customer Services

\section{in Cambridge:}

Phone $+44(0) 1223326070$

$\mathrm{Fax}+44(0) 1223325150$

Email journals@cambridge.org

\section{in New York:}

Phone +1 (845) 3537500

Fax +1 (845) 3534141

Email

subscriptions_newyork@cambridge.org 


\section{CAMBRIDGE}

\section{JOURNALS}

\section{Proceedings of the Royal Society of Edinburgh, Section A: Mathematics}

Marketed and Distributed for the Royal Society of Edinburgh

\section{Chairman and Executive Editor}

B. P. Rynne, Heriot-Watt University, UK

A flagship publication of The Royal Society of Edinburgh, Proceedings $A$ is a prestigious, general mathematics journal publishing peer-reviewed papers of international standard across the whole spectrum of mathematics, but with the emphasis on applied analysis and differential equations. An international journal, publishing six issues per year, Proceedings A has been publishing the highestquality mathematical research for nearly 70 years. Recent issues have included a wealth of key contributors and considered research papers.

\section{Price information}

is available at: http://journals.cambridge.org/prm

\section{Free email alerts}

Keep up-to-date with new material - sign up at http://journals.cambridge.org/prm-alerts

To subscribe contact Customer Services

\section{in Cambridge:}

Phone $+44(0) 1223326070$

$\mathrm{Fax}+44(0) 1223325150$

Email journals@cambridge.org

in New York:

Phone +1 (845) 3537500

Fax +1 (845) 3534141

Email

subscriptions_newyork@cambridge.org 


\section{CAMBRIDGE}

\section{JOURNALS}

\section{Proceedings of the Edinburgh Mathematical Society}

Published for The Edinburgh Mathematical Society

\section{Editorial Management}

The Secretary, ICMS, Edinburgh, UK

The Edinburgh Mathematical Society was founded in 1883 and over the years, has evolved into the principal society for the promotion of mathematics research in Scotland. The Society has published its Proceedings since 1884. This journal contains research papers on topics in a broad range of pure and applied mathematics, together with a number of topical book reviews.

\section{Price information}

is available at: http://journals.cambridge.org/pem

\section{Free email alerts}

Keep up-to-date with new material - sign up at http://journals.cambridge.org/pem-alerts

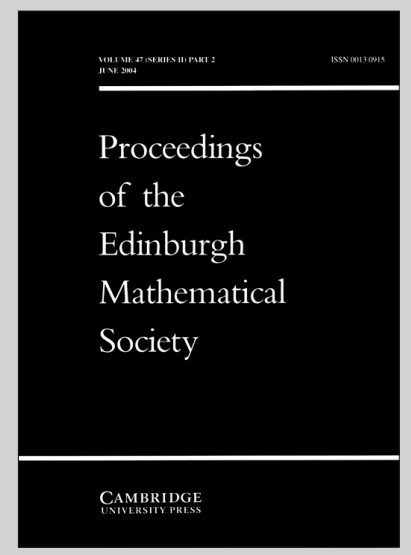

Proceedings of the Edinburgh Mathematical Society is available online at: http://journals.cambridge.org/pem

To subscribe contact Customer Services

\section{in Cambridge:}

Phone +44 (0)1223 326070

Fax $+44(0) 1223325150$

Email journals@cambridge.org

in New York:

Phone +1 (845) 3537500

Fax +1 (845) 3534141

Email

subscriptions_newyork@cambridge.org 


\section{CAMBRIDGE}

\section{JOURNALS}

\section{Glasgow Mathematical Journal}

Published for

The Glasgow Mathematical Journal Trust

\section{Editor-in-Chief}

I. A. B. Strachan, University of Glasgow, UK

Glasgow Mathematical Journal publishes original research papers in any branch of pure and applied mathematics. An international journal, its policy is to feature a wide variety of research areas, which in recent issues have included ring theory, group theory, functional analysis, combinatorics, differential equations, differential geometry, number theory, algebraic topology, and the application of such methods in applied mathematics.

\section{Price information}

is available at: http://journals.cambridge.org/gmj

\section{Free email alerts}

Keep up-to-date with new material - sign up at http://journals.cambridge.org/gmj-alerts

Glasgow Mathematical Journal

To subscribe contact Customer Services

\section{in Cambridge:}

Phone +44 (0)1223 326070

$\mathrm{Fax}+44(0) 1223325150$

Email journals@cambridge.org

\section{in New York:}

Phone +1 (845) 3537500

$\mathrm{Fax}+1(845) 3534141$

Email

subscriptions_newyork@cambridge.org 


\section{INFORMATION FOR AUTHORS}

The Bulletin of the Australian Mathematical Society aims at quick publication of original research in all branches of mathematics. To ensure speedy publication, only articles which are sufficiently well presented, able to be published without revision, and which are judged by the Editor (often in consultation with an Associate Editor) to be competitive are refereed. This policy is in the interests of authors, as a quick rejection is better than a slow rejection. The Bulletin receives more than five times the material that can be published, therefore there are many commendable papers not accepted. Editorial decisions on acceptance or otherwise are taken quickly, normally within a month of receipt of the paper. Papers are accepted only after peer review.

Manuscripts are accepted for review with the understanding that the same work is not concurrently submitted elsewhere. For a paper to be acceptable for publication, not only should it contain new and interesting results, but also

(i) the exposition should be clear and attractive, and

(ii) the manuscript should be in publishable form, without revision.

Further information regarding these requirements may be found through our website www.austms.org.au/Bulletin. Authors are asked to avoid, as far as possible, the use of mathematical symbols in the title.

Articles should be prepared in LTEX using $\mathcal{A}_{\mathcal{M}} \mathcal{S}$-IATEX packages and submitted as a PDF file via our journal management system, at www.austms.org.au/Publications/Submissions/BAustMS. This permits authors to track their papers through the editorial process. Recent versions of $\mathrm{T}_{\mathrm{E}} \mathrm{X}$ are able to produce PDF files directly. A LATEX class file for the Bulletin can be downloaded from the website. Authors who need assistance may email the secretary of the Bulletin at jams@ms.unimelb.edu.au.

Authors are advised to keep copies of all files of the submitted article; the Bulletin will not accept responsibility for any loss.

\section{EDITORIAL POLICY}

1. References. Arrange references alphabetically (by surname of the first author) and cite them numerically in the text. Ensure the accuracy of the references: authors' names should appear as in the work quoted. Include in the list of references only those works cited, and avoid citing works which are in preparation or submitted. Where the work cited is not readily accessible (for example, a preprint) a copy of the article should be included with your submission.

\section{Abstracts.}

1. Each paper must include an abstract of not more than 150 words, which should contain a brief but informative summary of the contents of the paper, but no inessential details.

2. The abstract should be self-contained, but may refer to the title.

3. Specific references (by number) to a section, proposition, equation or bibliographical item should be avoided.

3. Subject Classification and Key Words. Authors should include a few key words and phrases and one or more classification numbers, following the American Mathematical Society 2010 Mathematics Subject Classification for all codes. Details of this scheme can be found on the web at www.ams.org/msc.

4. Abstracts of PhD Theses. The Bulletin endeavours to publish abstracts of all accepted Australasian $\mathrm{PhD}$ theses in mathematics. One restriction, however, is that the abstract must be received by the Editor within six months of the degree being approved.

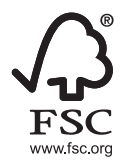

This journal issue has been printed on FSC-certified paper and cover board. FSC is an independent, non-governmental, not-for-profit organisation established to promote the responsible management of the world's forests. Please see www.fsc.org for information. 


\section{Table of Contents}

The strong dual of measure algebras with certain locally convex topologies

Javanshiri, H. Eं Nasr-Isfahani, $R$.

Existence results for a class of abstract impulsive differential equations

Hernández, E. EO O’Regan, D.

Complete spacelike submanifolds in de Sitter spaces with $\boldsymbol{R}=\boldsymbol{a H}+\boldsymbol{b}$

Liu, J. Eं Zhang, J.

On the positivity of Riemann-Stieltjes integrals

Lukkarinen, J. E Pakkanen, M. S.

New reductions and logarithmic lower bounds for the number of conjugacy classes in finite groups

Bertram, E. A.

Some properties of a sequence analogous to Euler numbers

Sun, Z.-H.

On the order of arc-stabilisers in arc-transitive graphs, II

Verret, $G$.

Note on odd multiperfect numbers

Dai, L.-X., Pan, H. E Tang, C.-E.

Self-approximation for the Riemann zeta function

Nakamura, T. Ẽ Pańkowski, t.

Centralisers in the infinite symmetric inverse semigroup

Konieczny, J.

Local-global principle for the finiteness and artinianness of generalised local cohomology modules

Fathi, A.

Notes on $K$-topological groups and homeomorphisms of topological groups

Wang, $H$. E $H e, W$.

The probability that $x^{m}$ and $y^{n}$ commute in a compact group

Hofmann, K. H. E Russo, F. G.

On a class of monomial ideals

Borna, K. EJ Jafari, $R$.

\section{Corrigendum/Erratum}

Correction to 'Sum-product estimates and multiplicative orders of $\gamma$ and $\gamma+\gamma^{-1}$ in finite fields'

Shparlinski, I.

Author Index for Volume 87 